\title{
Catalytic Synthesis of Arylisocyanates from Nitroaromatics. A Computational Study
}

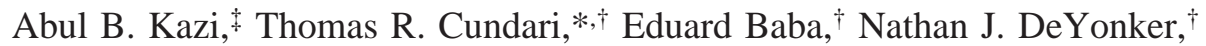 \\ Adriana Dinescu, ${ }^{\dagger}$ and Lloyd Spaine ${ }^{\dagger}$ \\ Department of Chemistry and Center for Advanced Scientific Computing and Modeling (CASCaM), \\ University of North Texas, P.O. Box 305070, Denton, Texas 76203-5070 and Department of Chemistry, \\ University of Arkansas Pine Bluff, Pine Bluff, Arkansas 71601
}

Received August 22, 2006

\begin{abstract}
Several conclusions of interest have emerged from a computational study of copper-catalyzed phenylisocyanate synthesis from nitrobenzene and carbon monoxide. Nitrobenzene complexes coordinate in a $\kappa^{1}-\mathrm{O}$ fashion, while nitrosobenzene complexes generally coordinate in a $\kappa^{1}-\mathrm{N}$ fashion. With regard to thermodynamics, differences were observed for neutral (amidate, amidinate, $\beta$-diketiminate) versus cationic (diimine, NHC) complexes, although discernible trends were less evident for calculated kinetic barriers. The deoxygenation of the nitroso oxygen of the nitrosobenzene complex to form a coppernitrene intermediate is postulated to be the rate-determining step. For the mechanism assumed in eqs 2 through 5, each step is exothermic. These individual steps are also calculated to possess reasonable kinetic barriers. Hence, copper-based complexes deserve consideration as potential catalysts for the phosgenefree synthesis of arylisocyanates from nitroaromatics.
\end{abstract}

\section{Introduction}

Aryl isocyanates are important chemical intermediates used in the synthesis of a variety of industrially important products such as polyisocyanates and polyurethanes. ${ }^{1}$ The manufacture of isocyanates involves the reduction of nitroaromatics to the corresponding anilines. This is then followed by reaction of the aniline with phosgene to yield the isocyanate. Several obvious drawbacks exist with such a process. ${ }^{1}$ First, phosgene is a poisonous gas. Second, the use of phosgene introduces chlorinated byproducts. Third, reaction of phosgene with anilines produces large quantities of corrosive $\mathrm{HCl}$. Isocyanates and other products resulting from the reduction of nitroaromatics such as ureas and carbamates are important precursors for herbicides and polymers such as polyurethanes. ${ }^{1}$ Important examples are provided by the compounds 2,4-toluene diisocyanate (TDI) and methylene-4,4'-diphenyl diisocyanate (MDI), which are starting materials for the synthesis of polyurethanes. ${ }^{1}$

There has been considerable interest in phosgene-free processes for the production of isocyanates from nitroaromatics. Two excellent reviews are available. ${ }^{2,3}$ Hardy and Bennett report the conversion of phenyl and substituted phenyl ( $o$ - and $p$-Me, $\left.m-\mathrm{Cl}, m-\mathrm{CF}_{3}, m-\mathrm{CN}\right)$ nitro compounds to the corresponding isocyanates using a noble metal catalyst and a Lewis acid cocatalyst. ${ }^{4}$ Tsumura et al. filed a patent for the production of aryl isocyanates from nitroaromatics by their reaction with $\mathrm{CO} .{ }^{5}$ Noble metal catalysts were described; $\mathrm{CuO} \cdot \mathrm{MoO}_{3}$ was utilized as a cocatalyst. ${ }^{1}$ Moiseev et al. reported the production of phenyl isocyanate from nitrobenzene through the use of a Pd cluster catalyst; nitrenes were implicated as intermediates in this

\footnotetext{
* Corresponding author. E-mail: tomc@unt.edu.

$\dagger$ University of North Texas.

$\div$ University of Arkansas Pine Bluff.

(1) Tafesh, A. M.; Weiguny, J. Chem. Rev. 1996, 96, 2035.

(2) Paul, P. Coord. Chem. Rev. 2000, 203, 269

(3) Tafesh, A. M.; Weiguny, J. Chem. Rev. 1996, 96, 2035.

(4) Hardy, W. B.; Bennett, R. P. Tetrahedron Lett. 1967, 11, 961.
}

transformation. ${ }^{6}$ Copper is an attractive catalyst for isocyanate formation due to its "green" nature and the reports in the literature of decarbonylation with copper-based catalysts. Doyle has reported the decarbonylation of formate esters by a copper catalyst. ${ }^{7}$ Liu et al. discuss the formation of aryl isocyanates from alkyl-nitro complexes by a copper zeolite catalyst. ${ }^{8}$ Kober et al. report the formation of halogenated arylisocyanates from halogenated nitroaromatics using a catalyst that is $5 \% \mathrm{PdCl}_{2}$ and $5 \% \mathrm{CuCl}_{2}$ supported on $\mathrm{SiC} .^{9}$

Copper catalysts are also widely used for nitrene transfer, including, among others, transfer of nitrenes to unsaturated organic substrates such as olefins, ${ }^{10}$ and thus make attractive targets for nitrene transfer to CO to yield isocyanates. Several researchers have demonstrated the feasibility of aryl isocyanate synthesis by the reaction of $\mathrm{CO}$ with aryl-imido/nitrene complexes of the late transition metals. Hillhouse and co-workers have reacted a bis(phosphine)Ni-nitrene with $\mathrm{CO}$ to form aryl isocyanates. ${ }^{11}$ Bart et al. ${ }^{12}$ and Peters et al. ${ }^{13}$ have reported nitrene group transfer from structurally characterized late transition metal-nitrene complexes (i.e., cobalt and iron) to $\mathrm{CO}$ to yield arylisocyanates.

The present research seeks to investigate novel copper catalysts for phosgene-free production of arylisocyanates (ArN$\mathrm{CO})$ from nitroaromatics $\left(\mathrm{ArNO}_{2}\right)$. The impact of ligands on

(5) (a) Tsumura, R.; Takagi, U.; Masaki, T.; Ikeda, K. Jpn. Kokai Tokkyo Koho JP 78-67629, 1979. (b) Izumi, Y. Jpn. Kokai Tokkyo Koho JP 90198013, 1992. (c) Grolig, J.; Rasp, C.; Scharfe, G.; Swodenk, W. Ger. Offen. DE 77-2750282 19771110, 1979, 18 pp.

(6) Moiseev, I. I.; Stromnova, T. A.; Vargaftik, M. N.; Orlova, S. T.; Chernysheva, T. V.; Stolarov, I. P. Catal. Today 1999, 51, 595.

(7) Doyle, G. U.S. Patent, US 4319050 A, 1982.

(8) Liu, I. O. Y.; Cant, N. W. J. Catal. 2005, 230, 123. Liu, I. O. Y.; Cant, N. W.; Haynes, B. S.; Nelson, P. F. J. Catal. 2001, 203, 487.

(9) Kober, E. H.; Martin, R. H.; Raymond, M. A. U.S. Patent US 3884952 19750520, 1975, 5 pp.

(10) Muller, P.; Fruit, C. Chem. Rev. 2003, 103, 2905. Vedernikov, A. N.; Caulton, K. G. Chem. Commun. 2004, 2, 162.

(11) Mindiola, D. J.; Hillhouse, G. L. Chem. Commun. 2002, 1840.

(12) Bart, S. C.; Lobkovsky, E.; Bill, E.; Chirik, P. J. J. Am. Chem. Soc. 2006, 128, 5302 . 
reaction kinetics and thermodynamics will also be investigated with computational chemistry. A key target of this research is to evaluate potential routes from $\mathrm{ArNO}_{2}$ to $\mathrm{ArNCO}$ and the intermediacy of nitroso compounds (ArNO) and nitrene complexes $\left(\mathrm{L}_{n} \mathrm{Cu}(\mathrm{NAr})\right)$ in these routes. Furthermore, the effect of the supporting ligand $\left(\mathrm{L}_{\mathrm{n}}\right)$ on reaction thermodynamics and kinetics is investigated.

\section{Computational Methods}

Semiempirical quantum mechanics (SEQM) methods, specifically the PM3(tm) Hamiltonian, ${ }^{14}$ were employed to generate starting geometries for subsequent higher-level calculations. The PM3(tm) method has been shown to be successful for the calculation of equilibrium geometries of transition-metal inorganic and organometallic compounds. ${ }^{15}$ The next step in the protocol is further refinement of the geometries by optimizing with density functional theory $\left(\mathrm{DFT}^{16}\right)$ methods, ${ }^{17,18}$ specifically the B3LYP/CEP-31G(d) level of theory for the remainder of the species considered herein. Vibrational frequencies were calculated at all DFT-optimized stationary points to confirm them as minima (no imaginary frequencies) or transition states (one and only one imaginary frequency). Calculation of the intrinsic reaction coordinates confirmed that the calculated transition states connected the appropriate reactants and products. Modeling of triplet species with density functional theory employed unrestricted Kohn-Sham methods. The ccCA composite method ${ }^{19}$ utilizes correlation consistent basis sets, a sequence of MP2 and QCISD(T) (or CCSD(T)) computations, plus a complete basis set (CBS) extrapolation scheme. The ccCA method has been shown to reproduce energetics for main group compounds with a MAD (mean absolute deviation) of less than 1 $\mathrm{kcal} \mathrm{mol}{ }^{-1}$ without the need for a high-level correction. ${ }^{19}$ DFT and correlation consistent composite approach $\left(\mathrm{ccCA}^{19}\right)$ calculations utilized the Gaussian $03^{20}$ suite of programs. Calculations employing PM3(tm) methods utilized the Spartan '04 package. ${ }^{21}$

\section{Results}

1. Thermodynamics of Uncatalyzed Reaction. The uncatalyzed decarbonylation of nitrobenzene to $\mathrm{PhNCO}$, eq 1 , is

$$
\mathrm{PhNO}_{2}+3 \mathrm{CO} \rightarrow \mathrm{PhNCO}+2 \mathrm{CO}_{2}
$$

computed to be very exothermic. Using the gas-phase enthalpies of formation in the NIST compendium, ${ }^{22}$ a reaction enthalpy of $-129 \mathrm{kcal} / \mathrm{mol}$ is predicted for eq 1 . In conjunction with the B3LYP functional, Stevens' compact effective potentials (CEPs)

(13) (a) Iron: Brown, S. D.; Betley, T. A.; Peters, J. C. J. Am. Chem. Soc. 2003, 125, 322-323. (b) Cobalt: Jenkins, D. M.; Betley, T. A.; Peters, J. C. J. Am. Chem. Soc. 2002, 124, 11238-11239.

(14) (a) Hehre, W. J.; Yu, J. 210th ACS National Meeting, Chicago, IL August 20-24, 1995, COMP-077. (b) Hehre, W. J.; Yu, J. 211th ACS National Meeting, New Orleans, LA, March 24-28, 1996, PMSE-216.

(15) Cundari, T. R.; Deng, J. J. Chem. Inf. Comput. Sci. 1999, 39, 376

(16) Koch, W.; Holthausen, M. C. A Chemist's Guide to Density Functional Theory; Wiley: New York, 1999.

(17) Becke, A. D. J. Chem. Phys. 1993, 98, 5648.

(18) Lee, C.; Yang, W.; Parr, R. G. Phys. Rev. B 1988, 37, 785.

(19) DeYonker, N. J.; Cundari, T. R.; Wilson, A. K. J. Chem. Phys. 2006, 124, 114104. DeYonker, N. J.; Grimes, T.; Yockel, S.; Dinescu, A.; Mintz, B. J.; Cundari, T. R.; Wilson, A. K. J. Chem. Phys. 2006, 125, 104111. Ho, D. S.; DeYonker, N. J.; Cundari, T. R.; Wilson, A. K. J. Phys. Chem. A 2006, 110, 9767.

(20) Frisch, M. J.; Pople, J. A.; et al. Gaussian 03, Revision C.02; Gaussian Inc.: Wallingford, CT, 2004.

(21) Spartan modeling package; Wavefunction, Inc.: Irvine, CA, 2004 (22) Afeefy, H. Y.; Liebman, J. F.; Stein, S. E. Neutral Thermochemical Data. In NIST Chemistry WebBook, NIST Standard Reference Database Number 69; Linstrom, P. J., Mallard, W. G., Eds.; June 2005, National Institute of Standards and Technology: Gaithersburg, MD 20899 (http:// webbook.nist.gov). and valence basis sets ${ }^{23}$ yield a value that is less exothermic than the experimental estimate for eq 1: B3LYP/CEP-121G(d), $\Delta H_{\mathrm{rxn}}=-117 \mathrm{kcal} / \mathrm{mol}$; B3LYP/CEP-31G(d), $\Delta H_{\mathrm{rxn}}=$ $-118 \mathrm{kcal} / \mathrm{mol}$. Analogous all-electron basis sets (e.g., B3LYP/ 6-31G(d), $\left.\Delta H_{\mathrm{rxn}}=-132 \mathrm{kcal} / \mathrm{mol}\right)$ tend to be closer to the experimental estimate than the CEP computations. The reaction enthalpy for eq 1 is $-132 \mathrm{kcal} / \mathrm{mol}$ when B3LYP methods are used with an extended Pople-style basis set such as B3LYP/6$311++\mathrm{G}(3 \mathrm{df}, 2 \mathrm{p})$. Using the ccCA method, ${ }^{19}$ which has been shown to reproduce energetics to within $\pm 1 \mathrm{kcal} / \mathrm{mol}$ without ad hoc corrections, the enthalpy of eq 1 is $-118 \mathrm{kcal} / \mathrm{mol}$, closer to the G3 and DFT/CEP predictions. Notwithstanding experimental and computational uncertainties, the uncatalyzed decarbonylation of $\mathrm{PhNO}_{2}$ to $\mathrm{PhNCO}$ is a very exothermic reaction.

2. Thermodynamics of Copper-Catalyzed Reactions. The following mechanism (eqs $2-5, \mathrm{~L}_{\mathrm{n}}=$ supporting ligand $=$ diimine, amidate, amidinate, $\beta$-diketiminate, or $\mathrm{N}$-heterocyclic carbene (NHC)) was investigated for the conversion of $\mathrm{PhNO}_{2}$ to $\mathrm{PhNCO}$.

$$
\begin{array}{r}
\mathrm{L}_{\mathrm{n}} \mathrm{Cu}+\mathrm{PhNO}_{2} \rightarrow \underset{\mathrm{n}}{\mathrm{L} \mathrm{Cu}\left(\mathrm{PhNO}_{2}\right)} \\
\text { complexation of nitroaromatic }
\end{array}
$$

$$
\begin{aligned}
\mathrm{L}_{\mathrm{n}} \mathrm{Cu}\left(\mathrm{PhNO}_{2}\right)+ & \mathrm{CO} \rightarrow \mathrm{L}_{\mathrm{n}} \mathrm{Cu}(\mathrm{PhNO})+\mathrm{CO}_{2} \\
& \text { formation of nitrosoaromatic complex }
\end{aligned}
$$

$\mathrm{L}_{\mathrm{n}} \mathrm{Cu}(\mathrm{PhNO})+\mathrm{CO} \rightarrow \mathrm{L}_{\mathrm{n}} \mathrm{Cu}(\mathrm{NPh})+\mathrm{CO}_{2}$ nitrene formation

$$
\begin{aligned}
\mathrm{L}_{\mathrm{n}} \mathrm{Cu}(\mathrm{NPh})+\mathrm{CO} \rightarrow & \mathrm{L}_{\mathrm{n}} \mathrm{Cu}+\mathrm{PhNCO} \\
& \text { product release/catalyst regeneration }
\end{aligned}
$$

Paul provides an exhaustive survey of the mechanistic possibilities for both direct and indirect reductive carbonylation of nitroaromatics to form arylisocyanates. ${ }^{2}$ After ligation of a nitroaromatic substrate to the catalyst (eq 2), reaction of the $\mathrm{PhNO}_{2}$ complex with $\mathrm{CO}$ yields the nitroso complex plus $\mathrm{CO}_{2}$ (eq 3). The nitroso complex is then deoxygenated by reaction with a second equivalent of $\mathrm{CO}$ to give a nitrene intermediate and $\mathrm{CO}_{2}$ (eq 4). The nitrene complex then inserts $\mathrm{CO}$ to yield an arylisocyanate product (eq 5) and regenerate the catalyst $\left(\mathrm{L}_{\mathrm{n}}{ }^{-}\right.$ $\mathrm{Cu}$ ). Although the exact details of the mechanism of catalytic conversion of $\mathrm{PhNO}_{2}$ to $\mathrm{PhNCO}$ have proven elusive, precedents exist for the individual steps. ${ }^{2,3}$ Issues to be addressed with computational chemistry include the following. What are the thermodynamics and kinetics of the individual steps? What is the rate-determining step? Is a carbonyl/nitrene complex a plausible intermediate in eq 5? Different linkage isomers may be close in energy for the $\mathrm{ArNO}_{2}$ and $\mathrm{ArNO}$ complexes $\left(\kappa^{1}-\mathrm{O}\right.$, $\kappa^{1}-\mathrm{N}, \eta^{2}-\mathrm{NO}$, etc.) formed in eq 2 and eq 3 , respectively. Do the different linkage isomers affect the energetics of the overall transformation? What is the effect of supporting ligand $\left(\mathrm{L}_{n}\right)$ on the individual reactions? Do spin-forbidden reactions play a role in the product-forming step (eq 5)?

a. Structure and Energetics of Nitrobenzene Complexes. From a computational perspective, organo-nitro (product of eq 2) and organo-nitroso (product of eq 3) complexes present interesting challenges vis-à-vis linkage isomerism ${ }^{24}$ given the multitude of coordination modes in which metal complexes of these entities have been structurally characterized. Nonchelating nitro-

(23) Stevens, W. J.; Basch, H.; Krauss, M.; Jasein, P. G. Can. J. Chem. 1992, 70, 610 .

(24) Buda, C.; Dinescu, C.; Kazi, A.; Cundari, T. R. J. Chem. Inf. Model. 2005, 45, 965. 
Table 1. B3LYP/CEP-31G(d) Enthalpies for Eqs 2-5 ( $\Delta H_{i}$, $i=2-5)$ with a Variety of Supporting Ligands $\left(\mathrm{L}_{\mathbf{n}}\right)$

\begin{tabular}{clcccc}
\hline$q^{a}$ & \multicolumn{1}{c}{$\mathrm{L}_{\mathrm{n}}$} & $\Delta H_{2}$ & $\Delta H_{3}$ & $\Delta H_{4}{ }^{b}$ & $\Delta H_{5}$ \\
\hline 0 & amidate & -29.1 & -48.1 & -27.8 & -12.6 \\
0 & amidinate & -23.3 & -49.9 & $-30.9^{c}$ & -13.4 \\
0 & $\beta$-diket & -14.7 & -47.3 & -33.3 & -22.2 \\
1 & diimine & -39.2 & -39.2 & -32.3 & -6.8 \\
1 & NHC & -45.7 & -37.0 & -31.4 & -3.5
\end{tabular}

${ }^{a}$ Overall charge of $\mathrm{Cu}$ complexes for each supporting ligand $\left(\mathrm{L}_{\mathrm{n}}\right) .{ }^{b}$ The nitrene products are triplets (all other reactants and products are singlets). ${ }^{c}$ Triplet-(amidinate $) \mathrm{Cu}(\mathrm{NPh})$ has a very small imaginary frequency $\left(v_{\mathrm{i}}=\right.$ $8 \mathrm{~cm}^{-1}$ ).

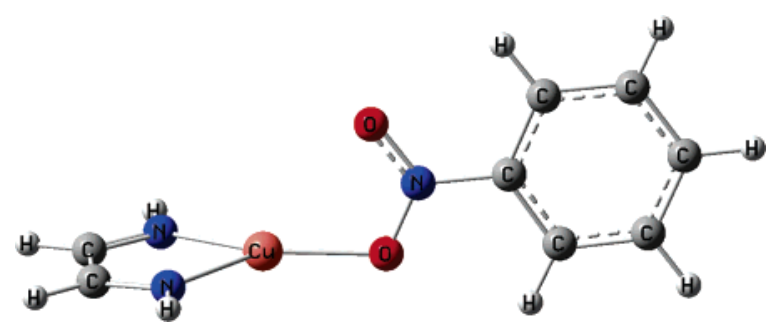

Figure 1. Computed structure of $\left[(\right.$ diimine $) \mathrm{Cu}\left(\kappa^{1}-\mathrm{O}-\right.$ nitrobenzene) $]^{+}$

aromatic ligands are found in both $\kappa^{1}-\mathrm{O}$ and $\eta^{2}$-NO coordination arrangements, with the former somewhat more prevalent. ${ }^{25}$ Inspection of the Cambridge Structural Database ${ }^{25}$ did not yield any examples of $\kappa^{1}-\mathrm{N}$ ligation of a nitroaromatic, consistent with a formal positive charge on the nitro nitrogen, and the loss of resonance that would result from $\kappa^{1}-\mathrm{N}$ coordination of $\mathrm{PhNO}_{2}$.

Geometry optimizations of $\mathrm{L}_{\mathrm{n}} \mathrm{Cu}\left(\mathrm{PhNO}_{2}\right)$ for the ligand models studied $\left(\mathrm{L}_{\mathrm{n}}=\right.$ diimine, amidate, amidinate, $\beta$-diketiminate, or $\mathrm{N}$-heterocyclic carbene (NHC)) were initiated from the $\kappa^{1}-\mathrm{O}, \kappa^{1}-\mathrm{N}$, and $\eta^{2}$-NO linkage isomers. The ligands were chosen on the basis of a survey of common ligand types for copper in the Cambridge Structural Database. ${ }^{25}$ In each case, the lowest energy linkage isomer is $\kappa^{1}-\mathrm{O}$. Enthalpies of binding of $\mathrm{PhNO}_{2}$ to copper catalyst models $\left(\Delta H_{2}\right.$ in Table 1$)$ are favorable, with the formation of the cationic complexes $\left[(\mathrm{NHC}) \mathrm{Cu}\left(\kappa^{1}-\mathrm{O}-\right.\right.$ $\left.\left.\mathrm{PhNO}_{2}\right)\right]^{+}$and $\left[(\text {diimine }) \mathrm{Cu}\left(\kappa^{1}-\mathrm{O}-\mathrm{PhNO}_{2}\right)\right]^{+}$being ca. $12 \mathrm{kcal} / \mathrm{mol}$ more exothermic, Table 1 . Nitrobenzene binding to the catalyst model is predicted to be weakest for ( $\beta$-diketiminate) $\mathrm{Cu}$, which is the only genuinely three-coordinate neutral complex. Amidate and amidinate complexes coordinate through a single nitrogen atom of the supporting ligand, reflecting the preference of $\mathrm{d}^{10}$ $\mathrm{Cu}^{+}$for linear, two-coordination. The cationic diimine complex (Figure 1) and the neutral $\beta$-diketiminate display trigonal planar $\mathrm{Cu}(\mathrm{I})$ coordination geometries, Figure 1 .

b. Structure and Energetics of Nitrosobenzene Complexes. The coordination chemistry of ArNO is dominated by the $\kappa^{1}-\mathrm{N}$ linkage isomer. ${ }^{25}$ However, examples of nitroso complexes have been structurally characterized that display $\kappa^{1}-\mathrm{O}, \mu_{2}-\mathrm{NO}, \eta^{2}$ $\mathrm{NO}, \mu_{2}-\eta^{2}, \mu_{2}-\eta^{2}, \eta^{2}$, and even $\mu_{2}-\eta^{2}, \sigma^{1}$ coordination. ${ }^{25}$ Geometry optimization of nitroso complexes was initiated from $\kappa^{1}-\mathrm{N}, \kappa^{1}-\mathrm{O}$ (with the phenyl group both cis and trans to $\mathrm{L}_{\mathrm{n}} \mathrm{Cu}$ ), and $\eta^{2}-\mathrm{NO}$ linkage isomers. In each case the $\kappa^{1}-\mathrm{N}$ isomer was predicted to be the most stable, consistent with the preeminence of this coordination mode in solid-state crystallography. ${ }^{25}$ Interestingly, for the $\beta$-diketiminate supporting ligand, the $\kappa^{1}-\mathrm{N}$ and $\eta^{2}-\mathrm{NO}$ linkage isomers are almost degenerate, with the $\eta^{2}$-NO being more stable by only $0.8 \mathrm{kcal} / \mathrm{mol}$, Figure 2 .

The reaction of the $\mathrm{PhNO}_{2}$ complex to yield the $\mathrm{PhNO}$ complex concomitant with conversion of $\mathrm{CO}$ to $\mathrm{CO}_{2}$ (eq 3) is

(25) Allen, F. H.; Davies, J. E.; Galloy, J. J.; Johnson, O.; Kennard, O.; Macrae, C. F.; Mitchell, E. M.; Smith, J. M.; Watson, D. G. J. Chem. Inf. Comput. Sci. 1992, 31, 187.
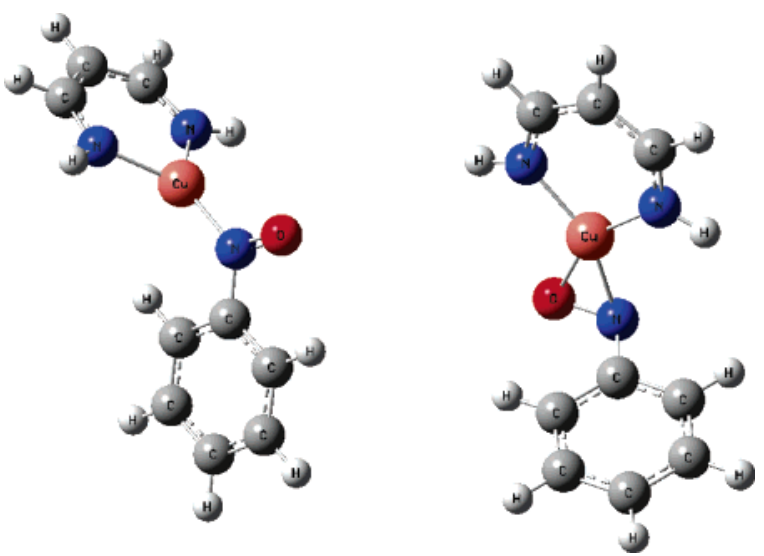

Figure 2. Computed low-energy linkage isomers of ( $\beta$-diketiminate) $\mathrm{Cu}(\mathrm{PhNO}): \kappa^{1}-\mathrm{N}$ linkage isomer (left) and $\eta^{2}$-NO linkage isomer (right). The $\eta^{2}$-NO linkage isomer is more stable than the $\kappa^{1}-\mathrm{N}$ linkage isomer by only $0.8 \mathrm{kcal} / \mathrm{mol}$.

computed to be highly exothermic $\left(\Delta H_{3}=-37\right.$ to $-50 \mathrm{kcal} /$ mol) for all copper complexes, Table 1 . As with the enthalpies for $\mathrm{PhNO}_{2}$-adduct formation, the only ligand-based differences are noted when comparing neutral and cationic complexes, the latter being $\sim 10 \mathrm{kcal} / \mathrm{mol}$ less exothermic for nitro to nitroso conversion, Table 1.

3. Copper-Nitrene Formation and Carbonylation. Coppernitrene complexes are expected to be key intermediates in the reaction sequence, as nitrenes of late transition metals such as $\mathrm{Fe},{ }^{12,13} \mathrm{Co},{ }^{13}$ and $\mathrm{Ni}^{11}$ are known to transfer $\mathrm{NR}$ to $\mathrm{CO}$ to yield isocyanates. Furthermore, Moiseev et al. implicated nitrenes as intermediates in this transformation. ${ }^{6}$ Density functional calculations indicate a triplet ground state for $\mathrm{L}_{\mathrm{n}} \mathrm{Cu}(\mathrm{NPh})$ for all ligands $\left(L_{n}\right)$ studied here. However, singlet states are calculated to be very close in energy by DFT methods (B3LYP/CEP-31G(d); calculated $\Delta H_{\mathrm{st}}$ range from $9 \mathrm{kcal} / \mathrm{mol}$ for [(diimine $\left.) \mathrm{Cu}(\mathrm{NPh})\right]^{+}$ to $14 \mathrm{kcal} / \mathrm{mol}$ for (amidate) $\mathrm{Cu}(\mathrm{NPh})$ ). The electronic structure of copper-nitrene complexes will be discussed more fully in a forthcoming paper. ${ }^{26}$ Copper-nitrenes are formed by deoxygenation of the nitrosobenzene complexes (eq 4) in the proposed mechanism. This second deoxygenation reaction $\left(\Delta H_{4}\right)$ is computed to be, on average, $\sim 13 \mathrm{kcal} / \mathrm{mol}$ less exothermic than the initial deoxygenation, i.e., that of the nitrobenzene complexes (eq 3 ).

The product formation step of the reaction involves the reaction of carbon monoxide with the nitrene complex to form arylisocyanate and regenerate the catalyst $\left(\mathrm{L}_{n} \mathrm{Cu}\right)$. Inspection of Table 1 shows the product formation step to be exothermic for all ligand sets investigated, although less exothermic than the other steps in the putative mechanism. The B3LYP/CEP-31G(d) enthalpies of the $\mathrm{PhNCO}$-forming step, eq 5, range from -4 $\mathrm{kcal} / \mathrm{mol}$ for the NHC complex to $-22 \mathrm{kcal} / \mathrm{mol}$ for the $\beta$-diketiminate complex.

Density functional calculations were carried out to probe the existence of a carbonyl-nitrene complex as a precursor to the $\mathrm{CO}$ insertions in the copper-nitrene bond. Such species are either unbound (i.e., $\mathrm{CO}$ dissociates upon geometry optimization for neutral complexes) or only marginally bound ( $\Delta H$ is small and negative for ionic compounds, but $\Delta G>0$ ). Hence, carbonylnitrene complexes do not seem to be bona fide precursors in the product formation step, and thus $\mathrm{CO}$ insertion likely occurs directly from $\mathrm{CO}$ and the copper-nitrene complex.

4. Transition States. Transition states were sought for all supporting ligation for reactions 3 through 5 using DFT methods (see Figure 3 for example of $\mathrm{L}_{\mathrm{n}}=\mathrm{NHC}$ ). The ligation of

(26) Cundari, T. R.; Kazi, A. B.; Dinescu, A. Manuscript in preparation. 


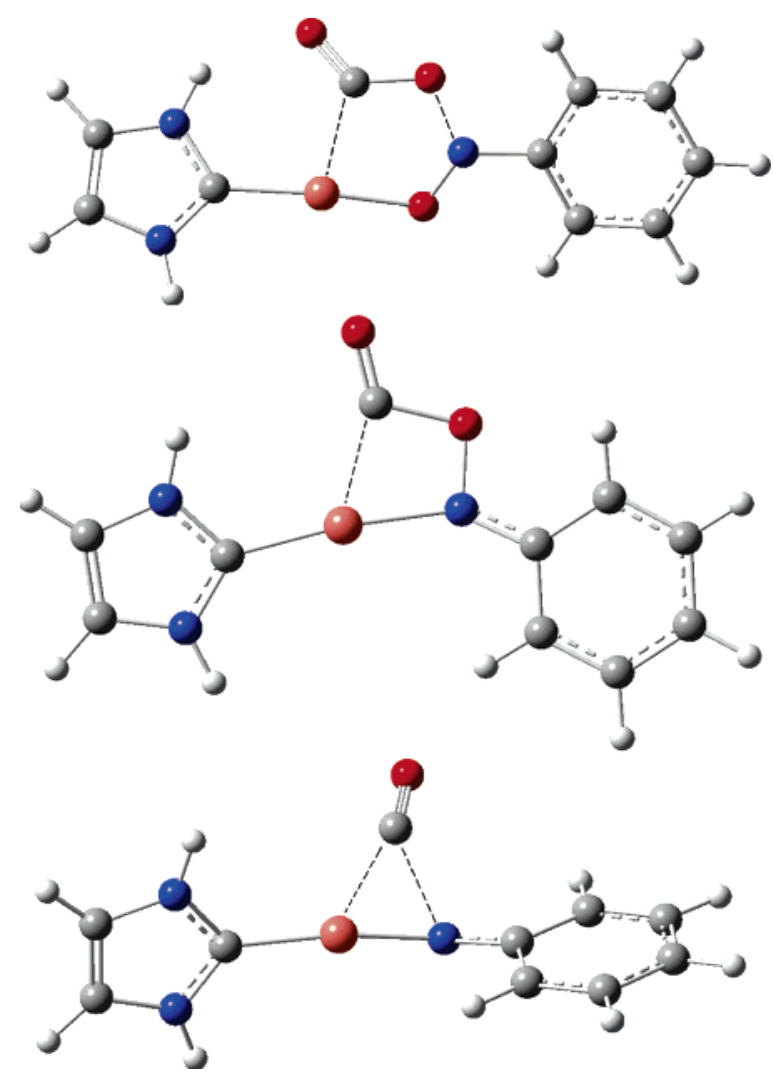

Figure 3. Calculated transition states are shown for deoxygenation of nitro complex (top, eq 3), deoxygenation of nitroso complex (middle, eq 4), and CO insertion into copper-nitrene bond (bottom, eq 5) for $\mathrm{L}_{\mathrm{n}}=\mathrm{N}$-heterocyclic carbene (NHC). Orange, red, blue, gray, and white spheres depict copper, oxygen, nitrogen, carbon, and hydrogen atoms, respectively.

Table 2. B3LYP/CEP-31G(d) Activation Enthalpies for Eqs 3-5 $\left(\Delta H^{\ddagger} i, i=3-5\right)$ with a Variety of Supporting Ligands

\begin{tabular}{lllc}
\multicolumn{4}{c}{$\left(\mathbf{L}_{\mathbf{n}}\right)$} \\
\hline ligand & $\Delta H^{\ddagger}{ }_{3}$ & $\Delta H^{\ddagger}{ }_{4}$ & $\Delta H^{{ }}{ }_{5}$ \\
\hline diimine & $b$ & 25.3 & 9.9 \\
NHC & 10.1 & 33.8 & 6.0 \\
amidate & $b$ & 30.8 & 2.9 \\
amidinate & 14.6 & 28.3 & 6.5
\end{tabular}

${ }^{a} \Delta H_{x}^{\ddagger}=$ Enthalpic barrier for eq $x$. The activation barrier for the productforming step is calculated relative to the singlet nitrene, $\mathrm{L}_{\mathrm{n}} \mathrm{Cu}(\mathrm{NPh})$. ${ }^{b}$ Transition states that could not be located despite the use of many different starting guess geometries and saddle point optimization techniques.

nitrobenzene substrate to $\mathrm{L}_{\mathrm{n}} \mathrm{Cu}$ (eq 2) was assumed to be barrierless. These searches were confined to the singlet surface. A few transition states eluded isolation, in particular those involving the $\beta$-diketiminate supporting ligation. When calculated reaction barriers are correlated with the computed thermodynamics, trends emerge that are instructive in terms of practical catalysts for phosgene-free production of arylisocyanates from nitroaromatics, Table 2. First and foremost, the ratedetermining step is found to be the deoxygenation (eq 4) of coordinated nitrosobenzene to yield a nitrene complex. Although the corresponding TS for the $\beta$-diketiminate could not be found, the second deoxygenation has enthalpic barriers $\left(\Delta H^{\ddagger}{ }_{4}\right)$ in the range of 25 (diimine) to 34 ( $\mathrm{NHC}$ ) $\mathrm{kcal} / \mathrm{mol}$ for the supporting ligands studied here, Table 2.

\section{Conclusions}

While gaps exist in the data due to our inability to find a few transition states (primarily those with $\mathrm{L}_{\mathrm{n}}=\beta$-diketiminate), the extant data allow us to predict that the cationic diimine complexes will yield the most active catalyst for a phosgene-free arylisocyanate synthesis operating through the mechanism assumed here. The barrier for deoxygenation of the [(diimine) $\left.\mathrm{Cu}\left(\kappa^{1}-\mathrm{N}-\mathrm{PhNO}\right)\right]^{+}$ complex has the lowest calculated barrier for the rate-determining step (eq 3). Interestingly, the other cationic complex investigated (i.e., $\mathrm{L}_{\mathrm{n}}=\mathrm{N}$-heterocyclic carbene) has the highest barrier for nitroso deoxygenation, suggesting that the three-coordinate nature of the $\mathrm{Cu}$-diimine complex yields enhanced steric pressure that facilitates the deoxygenation of the nitrosoaromatic substrate.

The results of DFT calculations for $\mathrm{L}_{n} \mathrm{Cu}(\mathrm{NPh})$ indicate a triplet ground state with a low-energy singlet excited state $\left(\Delta H_{\mathrm{st}}\right.$ $\approx 10 \mathrm{kcal} / \mathrm{mol})$. A triplet ground state for $\mathrm{L}_{\mathrm{n}} \mathrm{Cu}(\mathrm{NPh})$ may be expected to present potential difficulties for the proposed mechanism, as all other species on the potential energy surface are calculated to possess singlet ground states. Spin-orbit coupling is, of course, expected to be less efficient for copper as compared to the heavier coinage metals, silver or gold. However, the spin-orbit coupling coefficient $\left(\xi_{3 \mathrm{~d}}\right)$ of $\mathrm{d}^{9}-\mathrm{Cu}^{2+}$ is $829 \mathrm{~cm}^{-1}$, a value commensurate with $\xi_{4 \mathrm{~d}}$ for second-row transition metal ions such as $\mathrm{Ru}^{2+}$, but $\xi_{3 \mathrm{~d}}$ for $\mathrm{Cu}^{2+}$ is still onehalf the spin-orbit coupling coefficient for the corresponding silver ion. ${ }^{27}$ The results of DFT calculations on $\mathrm{L}_{n} \mathrm{Cu}(\mathrm{NPh})$ implicate a ground-state triplet with a low-energy singlet excited state. The optimized geometries of singlet and triplet states of $\mathrm{L}_{\mathrm{n}} \mathrm{Cu}(\mathrm{NPh})$ are similar. These pieces of computational evidence, when taken together with the large literature resources for copper-catalyzed nitrene transfer (most involving singlet products and reactants such as olefins and aziridines ${ }^{10}$ ), suggest that spin-forbidden reactions are not a major kinetic retardant for copper-mediated nitrene transfer.

The computed values of $\Delta H^{\ddagger}{ }_{4}$ are more than double the activation barriers for the first deoxygenation $\left(\Delta H^{\ddagger}{ }_{3}\right)$, which correlates with the computed thermodynamic trends (i.e., $\Delta H_{3}$ more exothermic than $\Delta H_{4}$, Table 1). The deoxygenation of nitrobenzene to yield coordinated nitrosobenzene (eq 3) is calculated to be more exothermic than the subsequent deoxygenation of the nitrosobenzene complexes to the corresponding copper-nitrene complexes (eq 4). Such a thermodynamic difference for $\mathrm{PhNO}_{2}$ versus $\mathrm{PhNO}$ deoxygenation is in harmony with the expected stronger $\mathrm{NO}$ bond strength for PhNO (bond order $\approx 2$ ) versus $\mathrm{PhNO}_{2}$ (bond order $\approx 1.5$ ). Using experimental enthalpic data ${ }^{22}$ allows us to estimate an NO bond enthalpy for nitrobenzene of $91 \pm 1 \mathrm{kcal} / \mathrm{mol}\left(\mathrm{PhNO}_{2} \rightarrow \mathrm{PhNO}\right.$ $+\mathrm{O})$, in excellent agreement with values obtained with the newly developed ccCA composite method, ${ }^{19} \mathrm{BDE}(\mathrm{NO})=93$ $\mathrm{kcal} / \mathrm{mol}$ for nitrobenzene using the ccCA-P and ccCA-S4 variants, which have been shown to reproduce energetics to within less than $1 \mathrm{kcal} / \mathrm{mol}$. These same ccCA methods indicate the NO bond of nitrosobenzene to be significantly stronger (i.e., $114 \mathrm{kcal} / \mathrm{mol}$ for both ccCA variants).

Computed barriers for the product-forming step (eq 5) are less than either of the two preceding steps. The B3LYP/CEP$31 \mathrm{G}(\mathrm{d})$-computed barriers for eq $5\left(\Delta H^{\ddagger}{ }_{5}\right)$ relative to the singlet $\mathrm{L}_{\mathrm{n}} \mathrm{Cu}(\mathrm{NPh})$ and $\mathrm{CO}$ are $3 \mathrm{kcal} / \mathrm{mol}$ for the neutral amidate complex up to $10 \mathrm{kcal} / \mathrm{mol}$ for the cationic diimine complex. Thus, the calculations indicate that formation of PhNCO from in situ-formed copper-nitrene and $\mathrm{CO}$ is quite facile, which is in keeping with experimental observations for other late transition metals, ${ }^{11-13}$ although support of this prediction for a copper complex would be of interest.

(27) (a) Berg, J. M.; McClure, D. S. J. Chem. Phys. 1989, 90, 3915. (b) Bendix, J.; Brorson, M.; Schaffer, C. E. Inorg. Chem. 1993, 32, 2838. 


\section{Summary}

Several conclusions of interest have emerged from this computational study of phenylisocyanate synthesis from nitrobenzene. The most significant are summarized here.

Nitro and Nitroso Complexes. Nitrobenzene complexes coordinate in a $\kappa^{1}-\mathrm{O}$ fashion, while nitrosobenzene complexes coordinate preferentially in a $\kappa^{1}-\mathrm{N}$ fashion with the exception of $\mathrm{L}_{\mathrm{n}}=\beta$-diketiminate, for which $\kappa^{1}-\mathrm{N}$ and $\eta^{2}$-NO linkage isomers are essentially degenerate.

Ligand Effects. With regard to thermodynamics, differences were observed for neutral (amidate, amidinate, $\beta$-diketiminate) versus cationic (diimine, NHC) complexes. Discernible energetics trends for neutral versus cationic complexes were less evident for calculated kinetic barriers.

Copper-Nitrenes. Low-energy singlet and triplet states were identified. The electronic structure and spin-state properties of copper-nitrenes deserve fuller examination ${ }^{26}$ with the use of more extensive multireference methods.

Spin-Forbidden Reactions. Although calculations indicate low-energy singlet and triplet states for the copper-nitrene intermediates, the close energy and structural similarity of these spin states, plus a reasonably high spin-orbit coupling constant for copper, suggest that kinetic impediments due to possible spin-forbidden processes will be minimal.

Rate-Determining Step. The deoxygenation of the nitrosobenzene complex to form a copper-nitrene intermediate is postulated to be the rate-determining step, a prediction that is consistent with a stronger $\mathrm{NO}$ bond for $\mathrm{PhNO}$ versus $\mathrm{PhNO}_{2}$. Moreover, the $\kappa^{1}-\mathrm{N}$ coordination model of $\mathrm{L}_{n} \mathrm{Cu}(\mathrm{PhNO})$ places the nitroso oxygen in an ideal position for its removal by $\mathrm{CO}$ reactant to produce $\mathrm{CO}_{2}$.

Thermodynamics and Kinetics. For the mechanism assumed in eqs 2 through 5, each step is individually exothermic. Individual steps are also calculated to possess reasonable kinetic barriers. Hence, copper-based catalysts deserve consideration for their potential catalytic role in the phosgene-free synthesis of arylisocyanates from nitroaromatics.

Acknowledgment. L.S. would like to thank the University of North Texas McNair Post Baccalaureate Research Program for providing support. The Center for Advanced Scientific Computing and Modeling (CASCaM) is supported through a grant from the U.S. Department of Education. This research was supported in part by a grant from the Offices of Basic Energy Sciences, U.S. Department of Energy (Grant No. DEFG02-03ER15387). Calculations employed the UNT computational chemistry resource, for which T.R.C. acknowledges the NSF for support through grant CHE-0342824. A.B.K. would like to acknowledge the UAPB administration and the UAPB Department of Chemistry for providing computational facilities.

OM060762O 